Hispania, 2014, vol. LXXIV, nº. 247, mayo-agosto, págs. 495-524

ISSN: 0018-2141, e-ISSN: 1988-8368, doi: 10.3989/hispania.2014.016

\title{
La sombra de la percepción: las autoridades coloniales británicas y francesas y el Protectorado español en Marruecos (1912-1936)
}

\author{
Pablo La Porte \\ Heriot-Watt University
}

RESUMEN: Este artículo explora elementos de percepción y falta de percepción en las relaciones internacionales en torno al Protectorado marroquí a comienzos del siglo XX. El artículo parte de la constatación de que estos elementos apenas han sido visitados por la historiografia del Protectorado español y arguye que su análisis clarifica algunos de sus extremos más enrevesados. Estas páginas afirman que existió en Marruecos un mundo variado de opiniones y percepciones, vivo y cambiante, sobre la colonización española, que afectó y se extendió a las autoridades coloniales de otros países europeos y cuya incidencia en las prioridades de politica colonial de sus respectivas metrópolis resultó significativa, así como la mediación e influencia de estas últimas en la aplicación de las mismas. Estos niveles de análisis ofrecen la oportunidad de enriquecer el conocimiento sobre la dimensión internacional del Protectorado español $y$ las dificultades y obstáculos a los que se enfrentó en el primer tercio del siglo XX. El artículo presenta cuatro dimensiones de la colonización española que se consideran fundamentales: su problemática legitimidad; las deficiencias y carencias del Ejército colonial de África; los vaivenes e indecisiones de la política colonial española, y el levantamiento de julio de 1936, que sirve de punto final al recorrido histórico que aquí se presenta. Se ha recogido información proveniente de archivos británicos y franceses para ilustrar los puntos de vista de sus representantes en Marruecos, así como las reacciones de sus respectivas metrópolis..

* Archives du Ministère des Affaires étrangères (ADMAE), La Courneuve. Centre d'accueil et de recherche des Archives nationales (CARAN), París. Centre des Archives diplomatiques de Nantes (CADN), Nantes. Public Record Office (PRO), Kew Gardens, London. Service historique de l'Armée de Terre (SHAT), Vincennes. Todas las traducciones son del autor. Agradezco a la Royal Society of Edinburgh su ayuda financiera para la elaboración de este trabajo. 


\title{
PAlABRAS ClaVE: Percepción y falta de percepción; relaciones inter- nacionales; protectorado marroquí; guerra del Rif; Lyautey; levantamiento de julio de 1936.
}

\section{Shadows of Perception: British and French Colonial Authorities and the Spanish Protectorate in Morocco (1912-1936)}

\begin{abstract}
This article explores elements of perception and misperception in international politics relating to the Moroccan Protectorate in the early $20^{\text {th }}$ century. It departs from the premise that such factors have been frequently overlooked by historians and argues that their study can clarify some of its most complex features. These pages claim that foreign officials in Morocco, particularly British and French, participated in the creation of a common set of values, beliefs and perceptions related to Spanish colonisation in Morocco which many of them shared, and which transpired in their reports to their governments. These perceptions not only influenced the recommendations and colonial policies emerging from metropoli, but also the course of action taken by colonial authorities in implementing them. The article outlines four fundamental issues of the Spanish Protectorate in Morocco: its problematic legitimacy, the shortcomings of the Ejército de África, the contradictions of Spanish colonial policy and the military uprising of 1936. Information from British and French archives has been used to support the arguments offered, which aim to enrich the understanding of international diplomacy in the Western Mediterranean in the early $20^{\text {th }}$ century and its implications for the Spanish Protectorate.

KEY WORDS: Perception and misperception; international relations; Moroccan Protectorate; Rif war; Lyautey; military uprising July 1936.
\end{abstract}

\section{INTRODUCCIÓN}

Cien años después de la firma del Convenio franco-español (1912) por el que se estableció la zona de influencia de España en Marruecos, y a juzgar por la frecuencia con que figura en libros, artículos académicos y medios de difusión asociados a las llamadas nuevas tecnologías (foros de debate, blogs), el colonialismo español sigue despertando interés entre los expertos y el público en general. Además de la renovada atención dedicada a su influencia en los orígenes y desarrollo de la guerra civil y la dictadura de Franco, las vicisitudes en las tensiones entre ambas orillas del Estrecho — desde el desafortunado incidente de la isla de Perejil (Laila) en 2002 hasta las cercanas reivindicaciones sobre la marroquinidad de Ceuta (Sebta) y Melilla (Mliliat) - y también el proceso de revisión reciente de la historia contemporánea de Marruecos, han situado el colonialismo español como punto de referencia hacia 
el que han gravitado una y otra vez argumentos e interpretaciones ${ }^{1}$. Ello ha inspirado iniciativas que han dado lugar, en algunos casos, a inesperados y espinosos problemas diplomáticos (en lo que se refiere al uso de armas químicas por parte del ejército español en la guerra del Rif, por ejemplo) y, en otros, a debates hasta entonces inéditos sobre el papel de las minorías en la historia marroquí. La discusión sobre la presencia colonial de España en Marruecos se ha revitalizado así, por una parte, y se ha diversificado por otra, extendiéndose sus ramificaciones por ambas orillas del Mediterráneo ${ }^{2}$.

En el marco de este reavivado interés, han sido particularmente abundantes las obras referidas al contexto internacional de la presencia española en Marruecos. Numerosos trabajos han destacado la rivalidad colonial entre Francia y España, las prioridades británicas en el área del Estrecho, el pragmatismo de la política exterior estadounidense en el Mediterráneo Occidental y las veleidades de diversas naciones europeas en la ciudad de Tánger como elementos particularmente influyentes en el desarrollo y vaivenes de la misma. El estudio del escenario internacional se ha visto así atraído predominantemente por las prioridades estratégicas y la defensa de los intereses nacionales de las diversas potencias involucradas, y también por las tensiones que produjeron sobre la colonización española. Se ha visitado a menudo, en definitiva, el aspecto geoestratégico de las relaciones internacionales en torno al Marruecos colonial, del que se han extraído importantes y acertadas conclusiones ${ }^{3}$.

Menos frecuente, sin embargo, ha sido la curiosidad acerca de las valoraciones de los representantes europeos presentes en Marruecos y sobre el papel que sus informes e impresiones tuvieron en la formulación de la política colonial metropolitana. Dichos representantes (sobre todo franceses y británicos) eran los más próximos a la labor colonial española y al desarrollo de sus iniciativas y, sin embargo, sus opiniones no han recibido profusa atención por parte de los investigadores, quizá porque se han considerado como un aspecto secundario o de una importancia relativa en el desenvolvimiento de las relaciones internacionales en el Mediterráneo Occidental ${ }^{4}$. Su importancia, sin

1 Véase MADARIAGA, 2002 y MECHBAL, 2 (2011), sobre la Guerra Civil, y CEMBRERO, 2006; LÓPEZ GARCÍA, 2007 y GILLESPIE, 15/1 (London, 2010): 85-103, sobre las tensiones diplomáticas recientes entre ambos países.

2 Véase BALFOUR, 2002 y KUNZ, 2004: 153-191, sobre la guerra química, y KAKI 68/1, (París, 2003): 103-118 y MADDY-WEITZMAN, 2011, sobre el papel de la minoría amazigh en el Marruecos contemporáneo.

3 Véase, PORCH, 18 (Leesburg, 2006): 28-37; SASSE, 2006; NEILA y PEREIRA, 34/1 (Bilbao, 2007): 117-154; PASTOR GARRIGUES, 23/1 (Murcia, 2007): 147-170 y MADARIAGA, 2009. Una compilación bibliográfica en LÓPEZ GARCÍA, 11 (2011): 136-141 y una reciente aportación en TUMA, 17:3 (2012): 433-453.

4 Éste es un aspecto del debate sobre el papel de la percepción y el error de percepción en los estudios de relaciones internacionales, que no ha dejado de estar presente desde la pu- 
embargo, resulta difícil de soslayar, ya que la percepción de la colonización española a los ojos de las autoridades coloniales extranjeras contribuyó a explicar de manera inequívoca las actitudes que adoptaron hacia la misma, así como el carácter de las recomendaciones enviadas a la metrópoli. Dichas apreciaciones ejercieron también una influencia significativa en el establecimiento de prioridades coloniales en las metrópolis europeas, así como en la aplicación y puesta en práctica de las mismas. La historiografía ha visitado algunos ejemplos en el Protectorado francés, donde la influencia del mariscal Lyautey en el Quai d'Orsay ha sido considerada como determinante. Existen, sin embargo, muchos otros casos en los que esta dimensión de la diplomacia internacional no ha recibido la importancia que merece 5 .

Este artículo considera que existió en Marruecos un mundo vivo y cambiante de opiniones y percepciones sobre la colonización española, del que participaron las autoridades coloniales británicas y francesas y cuya incidencia en las prioridades de política colonial de sus respectivas metrópolis resultó significativa. Se afirma también en estas páginas que estos niveles de análisis ofrecen la oportunidad de enriquecer el conocimiento sobre la dimensión internacional de la colonización española y las dificultades y obstáculos a los que se enfrentó en el primer tercio del siglo $\mathrm{XX}^{6}$. Se recogen en este trabajo cuatro dimensiones que se han considerado fundamentales de la misma: su problemática legitimidad; las deficiencias y carencias del Ejército colonial de África; los vaivenes e indecisiones de la política colonial, y, finalmente, el levantamiento de julio de 1936, que sirve de punto final al recorrido que aquí se presenta.

\section{LA PROBLEMÁTICA LEGITIMIDAD ESPAÑOLA: ¿UNA POTENCIA MENOR AJENA A LAS COORDENADAS IMPERIALES?}

La legitimidad de la presencia española en Marruecos constituye un punto de partida casi inevitable del tema, ya que la raíz misma de la misión colonial de España y el ejercicio de su autoridad dependía de la solidez de las reivindicaciones españolas y de la aceptación de las mismas por parte de otras po-

blicación de la obra ya clásica de JERVIS, 1976, y que continúa ofreciendo hoy interesantes ejemplos. Véanse GOLDGEIER y TETLOCK, 4 (Berkeley, 2001): 67-92; THOMAS, 17/4, (London, 2006a): 771-798 y FAURE, 2011: 99-115.

5 Sobre el peso de Lyautey en la política colonial francesa, pueden verse las obras de RIVET, 1988, vol. 3: 266-272; GERSHOVICH, 2000: 126-134; TEYSSIER, 2004: 389-390; SINGER y LANGDON 2004: 181-217 y BERENSON, 2011: 228-261.

6 Similares niveles de análisis se han aplicado con resultados excelentes a la trayectoria colonial de otros países. Véase BERMAN, 2004: 195-230; THOMAS, 21/5 (London, 2006b): 697-716, y OWEN, 38/1 (London, 2011): 1-6. 
tencias europeas. Las fuentes diplomáticas españolas de las primeras décadas de siglo reflejaron, sin embargo, sólo de manera parcial y limitada la complejidad de estas aspiraciones. Los derechos de España en Marruecos se refirieron insistentemente a la necesidad de proteger el entorno geográfico del Mediterráneo Occidental y a evitar una presencia francesa exclusiva (y amenazadora) al norte y al sur de la Península. La posesión histórica de los presidios de Ceuta y Melilla y los intereses estratégicos de España en la región galvanizaron así la postura española en la Conferencia de Algeciras (1906) y en las negociaciones del Tratado de Protectorado de 1912. Brevemente, la línea oficial de la diplomacia española en estos años se resumió en la idea de que España se encontraba en Marruecos «con plenos derechos históricos y en igualdad de condiciones con Francia», a pesar de las sinuosas aguas que la postura española había atravesado desde comienzos de siglo ${ }^{7}$. Éste fue el leitmotiv del Palacio de Santa Cruz desde el establecimiento del Protectorado marroquí (gobierno liberal de García Prieto de 1912) hasta el inicio de la guerra del Rif (gobiernos de concentración nacional de 1921). Las vacilaciones iniciales de Primo de Rivera ante la magnitud del conflicto (1923-1925) se vieron igualmente superadas, así como las reticencias iniciales de la Segunda República ${ }^{8}$.

Por debajo de estas consideraciones existían, sin embargo, elementos difíciles de ignorar, que las propias autoridades españolas admitieron en privado y que aparecieron frecuentemente en documentos diplomáticos franceses y británicos. Éstos hacían referencia a las escasas capacidades coloniales de España - la inercia y el atraso del país, su condición de nación moribunda, su ignorancia de los avances de la revolución industrial, el hecho de que el trasnochado colonialismo de España en América no fuera ya sino un vestigio del pasado enterrado en la derrota de Cuba- y a los problemas derivados de la misma. Admitiendo la legitimidad de sus reclamaciones históricas, numerosos comunicados e informes nacionales y extranjeros resaltaron el hecho de que la presencia de España en Marruecos obedecía más a un deseo de salvaguardar apariencias internacionales que a un verdadero impulso colonial, y que de ello podían extraerse consecuencias imprevisibles: «para bien o para mal —resumía el embajador británico en Madrid en 1912 - España estaba obligada a embarcarse en

7 Conde de Romanones, Ministro de Estado, a embajador británico en Madrid, Mr. Hardinge. (PRO FO legajo 371/11080, Hardinge a Balfour, 24/5/19). La presencia de los argumentos geo-estratégicos fue también una constante en el pensamiento africanista español del siglo XIX, que se reflejó en obras de autores tan diversos como Donoso Cortés, Cánovas (en sus años de juventud), Coello o Joaquín Costa. Véase PEDRAZ MARCOS, 2000: 39-66.

8 Sobre las prioridades de la diplomacia española en estas fechas pueden verse, entre otros, MORALES LEZCANO, 2002; DE LA MATA 24/1, (Murcia, 2008): 291-299, y MONTERO JIMÉNEZ, 25/1 (Madrid, 2011): 235-269. 
la aventura marroquí», idea que compartía el propio Mariscal Lyautey ${ }^{9}$. Estas referencias y prevenciones, conviene resaltarlo, recorrieron la totalidad del periodo que aquí se considera, desde los inicios y establecimiento de la zona de influencia española en Marruecos hasta los sucesos del año 36.

Conviene mencionar también que estas reflexiones de carácter geoestratégico y político sobre la idoneidad de España como poder colonial se enmarcaban en un contexto más amplio y de mayor recorrido histórico, en un proceso gradual de construcción intelectual sobre la alteridad del Oriente, que había comenzado a edificarse en diversos países europeos a comienzos del siglo XIX (Gran Bretaña, Francia) y cuyos perfiles fundamentales se habían definido ya a finales de siglo. Las asunciones y percepciones del orientalismo europeo sobre la esencia del Oriente, su identidad, espíritu y manifestaciones, se convirtieron en un terreno fértil sobre el que posteriormente surgirían teorías legitimadoras sobre la acción civilizadora europea en el mundo árabe y sobre la idoneidad de las distintas potencias coloniales para llevarla a cabo. En dicho proceso, el papel de España quedaría prontamente relegado a los márgenes históricos, asimilado al de un país cuyos peculiares rasgos y vitalidades nacionales (que isónicamente incluían muchos elementos «orientales»), se habían visto debilitados por una larga decadencia iniciada en el siglo XVII y cuyas últimas manifestaciones se habían hecho presentes en 1898. España se perfilaba así como un integrante desafortunado del grupo de naciones moribundas mencionado por Salisbury, incapacitada para llevar a cabo una acción colonial civilizadora y sumida en un profundo y radical proceso de introspección crítica sobre su lugar y papel en la modernidad ${ }^{10}$. Este bagaje cultural e ideológico no sólo se materializó en la pronta exclusión de España del reparto colonial (en buena medida recibida con aquiescencia tácita en la Península), sino que también dio lugar a numerosos comentarios y valoraciones sobre las potencialidades coloniales del país. Los ejemplos sobre estas aprehensiones, como se dijo, son abundantes y numerosos, y recorren una variedad de aspectos - la debilidad del colonialismo español, el uso de Marruecos como moneda de cambio para mantener un statu quo conveniente a Inglaterra en el Estrecho, la reinserción de España en el escenario europeo tras el desastre de Cuba como contrapartida en dicho intercambio-, que han sido frecuentemente visitados por la historiografía ${ }^{11}$. Otros permanecen aún en una relativa penumbra que quizá no se corresponde con su importancia.

9 Maurice de Bunsen a Grey, ministro de Exteriores, PRO FO, legajo 185/1141, 5/12/1912. La misma idea se refleja en ADMAE, Maroc (M), 1917-1940, legajo 197, Lyautey a Poincaré, 22/3/24.

10 Véase LABANYI, 5/3, (London, 2004): 229-243 y MARTIN-MÁRQUEZ, 2008:12-64.

11 JOVER ZAMORA, 1976: 138-145 y CHARMLEY, 1998: 157-163. 
El primero de los que se verán aquí se refiere al Mariscal Lyautey, Residente General de Francia en Marruecos y personaje histórico que no necesita presentación. Lyautey fue la máxima expresión del colonialismo «ilustrado» francés y la personificación del método de expansión indirecto a través de la cuidadosa alternancia de métodos de persuasión política e intervención militar. Su influencia en el Protectorado francés y en el Quai d'Orsay fueron determinantes en los 13 años en que ocupó la Residencia General de Rabat (1912-1925) y su tache d'huile se convirtió en un modelo para la «expansión pacífica» de los imperios europeos en el mundo árabe. Dada su posición en el pináculo de la administración colonial francesa - Lyautey fue incluso brevemente ministro de Guerra en 1917, como se recordará-, sus apreciaciones sobre la legitimidad de la presencia de España en Marruecos resultaron fundamentales. Mientras que los historiadores han dedicado suficiente atención a su visión colonial y a sus opiniones, generalmente derogatorias sobre la acción colonial española, las raíces de dicho pensamiento, relacionadas en algunos casos con motivaciones e interpretaciones particulares, no han gozado de similar interés ${ }^{12}$.

A comienzos de 1924, por ejemplo, en pleno desarrollo de la guerra del Rif que enfrentaba a los españoles contra las tribus comandadas por Abd el Krim, el Mariscal Lyautey redactó un documento en el que, con mayor claridad que en ninguna de sus comunicaciones anteriores, explicó de manera expresa su visión sobre la presencia española en Marruecos. Mientras que en otros despachos el Residente General francés se había limitado a ofrecer comentarios más o menos aislados o puntuales sobre la acción española — generalmente críticos-, en este informe presentó una visión general de largo recorrido sobre la presencia de España en Marruecos en la que incluyó consideraciones históricas y morales. Además de las dificultades de España como potencia colonial, Lyautey desarrolló en este documento su visión personal sobre la presencia española en Marruecos, que él ligaba a las propias (in)capacidades históricas de España como país y de los españoles como pueblo. Sus valoraciones incluían una interpretación general de la historia de España y una síntesis de las características fundamentales del «ser español», entre las que incluía «una extrema susceptibilidad», nacida de la evidencia de las propias limitaciones y una «hostilidad incontestable y sin escrúpulos» hacia los logros franceses ${ }^{13}$. Lyautey afirmaba, entre otras cosas, que la pre-

12 Este es el caso en las obras de RIVET,1988: 268-273 (que llegó hablar de la fobia de Lyautey hacia lo español); GERSOVICH, 2000: 125-127 y SEGALLA, 2009: 11-15.

13 Lyautey a agregado militar de la embajada francesa en España, P. de Cuverville, ADMAE, M, legajo 197, 4/3/24. Otros informes anteriores recogían valoraciones similares: CARAN, Fonds Lyautey (L), legajo 475 AP/90, a Poincaré, 29/7/12 y CADN, legajo CD52A, Lyautey a Delcassé, ministro de Exteriores, 22/9/15. 
sencia de España en Marruecos había sido entendida por parte de los españoles como una prolongación de la lucha secular establecida entre el Catolicismo y el Islam desde 711, conluyendo y que los españoles habían encontrado en Marruecos a su enemigo «natural e histórico» con el que pretendían continuar la irresuelta batalla entre la cruz y la espada. El orgullo congénito de los españoles y su negativa a aceptar el fin de la época gloriosa de las Américas habían encontrado así en Marruecos un horizonte de redención. Marruecos aparecía, por tanto, en la mentalidad española más como un escenario de luchas pasadas que como un horizonte de posibilidades futuras. De ahí lo que Lyautey consideraba una incapacidad fundamental de los españoles para comprender los presupuestos y las implicaciones del colonialismo moderno. De ahí también el hecho de que los musulmanes consideraran a España como «el enemigo hereditario» y de que los indígenas mostraran hacia los españoles «un odio y un desprecio en un grado difícil de concebir» ${ }^{14}$.

Otro ejemplo que puede ilustrar estas consideraciones sobre la problemática legitimidad española en Marruecos proviene de fuentes británicas, que, a menudo más pragmáticas en su visión, también ofrecieron valoraciones reveladoras sobre la presencia colonial de España. Entre ellas, y de manera preminente, se encuentran referencias clásicas al dominio imperial como manifestación de la superioridad cultural y racial de los pueblos europeos sobre otras civilizaciones, como expresión del liderazgo de los pueblos avanzados sobre las razas atrasadas y como resultado de la lucha por la supervivencia que dividía a las naciones desarrolladas de las naciones moribundas. Las dudas sobre la legitimidad española en Marruecos —que aparecieron particularmente en los informes del cónsul británico en Tetuán, Hope-Gill (quizá, junto con su sucesor, Monck-Mason, los representantes británicos más influyentes en Marruecos) - , se refirieron precisamente a la «fundamental incapacidad» de los españoles para comprender estos presupuestos y actuar de acuerdo con los mismos ${ }^{15}$. Las autoridades británicas criticaron particularmente las prácticas vejatorias con que se inició la administración colonial española en Marruecos (1912-1915), no tanto por su brutalidad intrínseca sino, sobre todo, por su falta de relación y correspondencia con lo que se entendían como los síntomas y métodos de civilizaciones avanzadas, que para ellas constituían la clave del edificio colonial. Del mismo modo, otros aspectos de la administración española, que tampoco parecían concordar con esa mentalidad y concepción imperial, también recibieron un frío trato por parte de las autoridades británicas. El «excesivo» acercamiento de la política colonial española al elemento indígena a partir de la llegada de la Segunda Repú-

14 Lyautey a Herriot. CARAN, L., legajo 475 AP/86, 8/10/24.

15 PRO FO, legajo 636/6, C.G. Hope Gill a Cónsul General en Tánger, Sir Malcolm A. Robertson, 17/7/24. 
blica, por ejemplo, produciría perplejidad en la diplomacia británica, e íntimo disgusto en algunos casos. Las demostraciones de afecto y efusiones públicas $\mathrm{y}$, particularmente, la referencia a los súbditos del Sultán como «hermanos de sangre» por parte de representantes de la Segunda República, serían recibidas en los círculos coloniales británicos con un radical escepticismo, que consideraba «la política española de tratar como iguales a los moros» como «equivocada y peligrosa» ${ }^{16}$.

Es suficientemente conocida la influencia que los puntos de vista de Lyautey ejercieron en el Quai d'Orsay en lo relativo a los conflictos de legitimidad entre Francia y España en Marruecos — su negativa a aceptar la denominación de «Protectorado español en Marruecos»; su referencia continua a la «zona de influencia» de España, sus críticas a las excesivas atribuciones del Jalifa en la zona española- ${ }^{17}$. La historiografía quizá no ha resaltado de manera explícita, sin embargo, que bajo dichas asunciones existía el peso decisivo de convicciones personales basadas en apreciaciones más o menos subjetivas sobre el sentido de la presencia española en Marruecos. A lo largo del conflicto del Rif, estas opiniones se pusieron de manifiesto en diversas ocasiones, particularmente cuando el Mariscal presentó a su gobierno propuestas que parecían contradecir los principios del Tratado de 1912, pero que estaban en consonancia con la escasa legitimidad que Lyautey otorgaba a España como potencia colonial en Marruecos. Su iniciativa de invadir la zona española, por ejemplo, formulada tras y la retirada decretada por Primo de Rivera en noviembre de 1924, era contraria a los tratados internacionales de 1912, pero estaba en sintonía profunda con una visión derogatoria sobre la presencia española en Marruecos. Los argumentos que Lyautey decía extraer de los acuerdos del Protectorado - el derecho de Francia a intervenir en la zona vecina cuando el colapso de la autoridad española amenazaba con dirigir a los rebeldes hacia la zona francesa-, tuvieron una influencia evidente en el go-

16 PRO FO, legajo 413/84, Mr Monck-Mason a ministro de Exteriores, Sir John Simon, 24/11/33. Véase también PRO FO, legajo 371/16483, informe anual, Mr. Gurney, secretario del Consulado General en Tánger, a Simon, 4/2/32.

17 De acuerdo con los términos del Tratado de 1912, correspondía a España una «zona de influencia» en Marruecos, sutilmente diferenciada del «Protectorado» que se reconocía a Francia. Mientras que la administración colonial española y los gobiernos de la Restauración prontamente equipararon la situación de ambos territorios, las autoridades coloniales francesas mantuvieron presente esta distinción, que pasó a incorporarse al conjunto de las diferencias, malentendidos y tensiones entre ambas administraciones en los años posteriores (RIVET, 1988: 266-272; GERSHOVICH, 2000: 126-134; SINGER Y LANGDON, 2004: 181-217). Dicho debate no sólo estuvo presente en el orden político y administrativo, sino que también pasó a formar parte de las polémicas entre los africanistas españoles y franceses, algunas de ellas continuadas hasta la propia independencia del país. Véase DÍAZ PINÉS Y FERNÁNDEZ-PACHECO, 1953. 
bierno francés, que llegó a apoyar inicialmente esta iniciativa antes de que la firme y decidida oposición británica le obligara a abandonarla ${ }^{18}$.

Las apreciaciones de las autoridades británicas en Marruecos encontraron también eco en los documentos oficiales elaborados por el Foreign Office, que coincidieron en señalar que las mayores dificultades que experimentaba España en Marruecos procedían de su incapacidad para presentarse ante los marroquíes como representantes de una superior civilización europea ${ }^{19}$. La constatación de estas carencias produjo preocupación en el Foreign Office, que entendía la presencia de España en Marruecos como una garantía contra las ambiciones francesas y a favor del mantenimiento del statu quo en el Estrecho. Las fuentes diplomáticas británicas se vieron así forzadas a manejar alternativas que emergían de las dudas y vacilaciones sobre la entidad y las capacidades coloniales de España, y que incluyeron también propuestas ajenas a los acuerdos de 1912, como, por ejemplo, un acomodamiento hipotético con las ambiciones italianas en el Mediterráneo occidental, particularmente en la ciudad de Tánger $^{20}$. Dichas alternativas fueron finalmente desechadas ante la terminante oposición francesa a las aspiraciones fascistas, pero no desaparecieron completamente del horizonte de las resoluciones del Foreign Office, sobre todo en los difíciles años de la guerra del Rif ${ }^{21}$.

En definitiva, el desafortunado y marginal papel de España en el horizonte y la mentalidad colonial europea de finales del siglo XIX se vio acompañado, en el caso de Marruecos, por valoraciones de representantes británicos y franceses emanadas de dichos presupuestos, pero que adoptaron formas y actitudes particulares. La influencia de las mismas en los centros de decisión de la política colonial francesa y británica tuvo la suficiente envergadura para cuestionar algunos extremos de los acuerdos internacionales sobre el Protectorado marroquí 22 .

18 Lyautey afirmaba «el derecho de Francia a intervenir fuera de su zona según las previsiones de los tratados» (ADMAE, M., legajo 199, Lyautey a Herriot, 19/12/24), postura que fue compartida por Herriot (ADMAE, M., legajo, 199, a Lyautey, 8/12/24). La presión británica ejercida por Sir Austen Chamberlain, ministro de Exteriores, fue finalmente decisiva para el abandono de estas aspiraciones (PRO FO, legajo 371/10854, minuta sobre la entrevista entre Chamberlain y Herriot, París, 5/12/24).

19 PRO FO, legajo 371/3838, Memorándum de Mr. Sperling, Departmanento de África, 3/9/1919 y PRO FO, legajo 371/4513, memorándum del ministro de Exteriores, G. N. Curzon, 26/8/20.

20 PRO FO legajo 371/3838, Memorándum de Mr. Sperling, 3/9/1919.

21 Chamberlain, por ejemplo, volvió a reavivar estas consideraciones en 1925. PRO FO legajo 371/11076, memorándum del 6/1/25.

22 Este aspecto pasa desapercibido en RIVET, 1988: 268-273; GERSOVICH, 2000: 125 127 y SEGALLA, 2009: 11-15; y también, hasta cierto punto, en THOMAS, 2005 y FISHER, 83/222 (London, 2010): 719-746. 


\section{LA «INEFICACIA IRRESOLUBLE» DEL EJÉRCITO COLONIAL DE ÁFRICA}

Al igual que en el caso de la legitimidad colonial de España, abundaron en las fuentes diplomáticas británicas y francesas descripciones previsiblemente negativas sobre el Ejército de África, que revelaron todos los aspectos imaginables de la incompetencia de un ejército colonial. Elementos sobradamente visitados por la historiografía - falta de recursos, equipamiento y entrenamiento de las tropas; desconocimiento del terreno, lengua y usos y costumbres de las tribus por parte de jefes y oficiales; falta de coordinación durante las operaciones; rivalidades entre junteros y africanistas - se pusieron de manifiesto una y otra vez en estos documentos, que no hicieron, por otra parte, sino reiterar lo que las fuentes militares españolas reconocían abiertamente ${ }^{23}$.

Existieron, sin embargo, diferencias de matiz en estas fuentes. Mientras numerosos observadores franceses parecían creer que el problema fundamental del Ejército de África se debía a su propia idiosincrasia — su crónica ineficacia, el hecho de que hubiera forzado la mano a los gobiernos de la Península para conseguir un papel destacado en Marruecos y recuperar así el prestigio perdido en Cuba (razón que fue utilizada incluso en diversas ocasiones por ministros y embajadores españoles para explicar la aparente independencia con que actuaba el Ejército de África con respecto al gobierno de Madrid) ${ }^{24}$-, documentos provenientes de las autoridades británicas ofrecieron otras consideraciones igualmente reveladoras. En ellos se presentaba una impresión en la que el ejército colonial español aparecía más como víctima de los despropósitos coloniales que como causante de los mismos. Junto con todas sus ineficiencias y carencias - repetidamente citadas - se señalaban las difíciles circunstancias en que el ejército colonial había sido puesto en Marruecos, donde la errática administración civil del territorio (inexistente inversión en educación, ausencia casi total de infraestructuras de transporte y corrupción general de las prácticas administrativas) presentaba obstáculos casi insuperables ${ }^{25}$. Aparecieron también elogios dirigidos a algunas unidades del Ejército colonial español, sobre todo de

23 Los ejemplos son numerosos. Pueden destacarse el informe del coronel Baird, agregado militar del consulado de Tetuán, a Sir Edward Grey, (PRO FO legajo 371/45276, 6/11); y el informe de Lyautey a Briand, ADMAE, M., legajo 620, 26/7/21. Una visión general de estas carencias se encuentra, por ejemplo, en BALFOUR, 2002: 83-120. Las críticas por la situación del Ejército de África se plasmaron frecuentemente en publicaciones africanistas y castrenses, de las cuales la más representativa fuera quizá la «Revista de Tropas Coloniales», fundada en Ceuta en 1924. Véase, por ejemplo, el artículo de su fundador, el general Gonzalo Queipo de Llano, «El problema de Marruecos. Al aparecer 'La Revista de Tropas Coloniales'», publicado en febrero de 1924.

24 Romanones a Gouraud, Residente General francés en Marruecos, 12/3/17 (CADN, CD168).

25 PRO FO legajo 413/58, M. de Bunsen, a Grey, 21/2/13. Otros informes similares en PRO FO legajo 413/59, consulado británico en Tánger, H. Kennard a Grey, 28/6/19. 
Regulares y la Legión, a quienes se consideraba «las únicas fuerzas fiables en las que se podía confiar para llevar a cabo el proceso de ocupación». ${ }^{26}$ Numerosos informes incidieron, en definitiva, en el hecho de que el ejército español había sido puesto en África en una posición imposible, falto de material y equipo, enfrentado a una opinión pública contraria en la Península y, al mismo tiempo, encargado de pacificar un territorio hostil y sin recursos — donde se esperaba que avanzara «sin pegar un tiro», por miedo a las repercusiones que ello pudiera causar en las Cortes, de acuerdo con el embajador británico en Madrid-.${ }^{27}$ Las simpatías que existían entre algunas autoridades británicas hacia el ejército colonial español se materializaron en frecuentes visitas al frente y a las autoridades militares españolas (en marcado contraste con la práctica de las autoridades francesas), así como en periódicos contactos con sus representantes, en los que abundaron opiniones y consejos, marcadamente condescendientes ${ }^{28}$.

Esta impresión contrastaba con la actitud dominante en el Protectorado francés, donde las valoraciones sobre el ejército español en África estaban basadas en otros presupuestos. La experiencia colonial previa (la rivalidad en la que se situó desde el inicio la penetración militar de Francia y España en Marruecos, por ejemplo) y el contraste evidente entre las dificultades del ejército español y los éxitos del ejército francés (algo que las fuentes coloniales francesas frecuentemente mencionaron) explicaron la distinta y distante actitud de las autoridades militares francesas hacia su vecino marroquí. La influencia de Lyautey como el más experimentado conocedor de los límites del ejército colonial español resultó fundamental en este estado de cosas. $\mathrm{Su}$ tendencia a contrastar y resaltar la diferencia entre los métodos coloniales franceses y los españoles y su reticencia a considerar la colaboración militar entre ambos ejércitos determinaron en buena medida el curso de las relaciones militares entre ambos protectorados: «Nuestra mejor oportunidad — gustaba de repetir Lyautey - es que los marroquíes no nos asocien en absoluto con los españoles» ${ }^{29}$. La pobre valoración general que existía en el Protectorado francés sobre el ejército de África no estaba basada tan sólo en aspectos operativos o estratégicos. Existían también agravios comparativos a los que el Mariscal Lyautey se refirió con frecuencia en sus informes y que remitían, en particular, a la actitud del ejército colonial español durante la Primera Guerra Mundial. Lyautey volvería repetidamente en sus informes sobre este particular en términos que dejaban pocas dudas sobre el profundo efecto que dicha

26 PRO FO legajo 636/7, Hope Gill a R. MacDonald, ministro de Exteriores, 26/9/24.

27 PRO FO legajo 185/1180, Hardinge a Grey, 3/7/14; y PRO FO legajo 371/2711, Hardinge a Grey, 5/5/16.

28 W.M. Codrington, encargado de negocios de Tánger, a Hope Gill (PRO FO legajo 636/7, 10/11/24) y Hope Gill a Chamberlain (PRO FO legajo 636/8, 26/11/24).

29 SHAT, legajo $3 \mathrm{H}, 132$, Lyautey a Poincaré $2 / 8 / 21$. Sobre las ventajas derivadas de dicha estrategia véase GERSHOVICH, 2000: 126 y ss. 
actitud había causado en él. En su opinión, las autoridades españolas habían permitido - tácitamente o con expresa benevolencia - la actuación de los agentes alemanes en su zona, convirtiendo así la zona de influencia española en Marruecos en otro frente abierto para Francia durante el conflicto. Durante el mismo, en definitiva, España había traicionado a Francia en Marruecos ${ }^{30}$.

Resulta interesante constatar aquí que la memoria de dicho conflicto y los efectos del mismo todavía perduraran en Lyautey en los años de la guerra del Rif, a pesar de los cambios que se habían introducido en la política y el ejército colonial español desde 1918. A mediados de los años 20 existían consideraciones estratégicas que desaconsejaban la colaboración militar ante la rebelión rifeña y que Lyautey se preocupó de resaltar - la necesidad de no inquietar a las tribus, que miraban con recelo los desarrollos del colonialismo en la zona española; la crónica ineficacia del ejército colonial español y la carga que de ella resultaría para el ejército colonial francés-, pero otras razones de tipo particular pueden explicar quizá más satisfactoriamente la firme y continuada negativa de Lyautey a contemplar siquiera entrevistas con los mandos del ejército español, incluso cuando ésta parecía ser el curso de acción más aconsejable. Sobre todo en algunos de sus escritos dirigidos a sus colaboradores más inmediatos, las convicciones personales de Lyautey —emanadas quizá de sus propias vicisitudes personales durante la Gran Guerra— parecieron ocupar un lugar central y primario en su negativa a aceptar la cooperación militar con los españoles. En ellos Lyautey llegó a afirmar, por ejemplo, que España «había recibido su merecido en el Rif» por la actitud pro-alemana que había demostrado durante la Primera Guerra Mundial y que nada era más conveniente para Francia que España «se derrumbara» en Marruecos ${ }^{31}$. Estas convicciones podrían ayudar a explicar así algunas de las contradicciones que más han llamado la atención de los estudiosos en la estrategia de Lyautey durante los años de la guerra del Rif. Su máxima tradicional y continuamente repetida de que Marruecos se asemejaba a una caja de resonancia en la que cualquier conflicto local reverberaría sobre todo el país, por ejemplo, se vio desplazada durante el conflicto del Rif por una negativa rotunda a establecer contactos y colaborar con los españoles (a pesar del efecto que la inestabilidad del Rif podía causar en la propia zona francesa, como se puso de manifiesto en 1925) ${ }^{32}$.

Los gobiernos franceses que afrontaron el conflicto del Rif valoraron altamente las opiniones de Lyautey y tendieron a apoyar sus indicaciones, hasta

30 ADMAE, M., legajo 197, Lyautey a Cuverville, 4/3/24. Véase también RIVET, 1988: 267-268; SINGER y LANDON, 2004: 205-206.

31 ADMAE, M., legajo 197, nota a P. de Cuverville, 4/3/24. Véase también CADN, legajo CD243, Lyautey a Poincaré, 21/3/24.

${ }^{32}$ Véase HOISINGTON, 1995: 185-192. El propio Briand, mencionó delicadamente estos extremos contradictorios en su correspondencia con el Mariscal (CARAN, L., legajo 475/AP 101, Briand a Lyautey, 5/12/21). 
el punto de que podría decirse que aceptaron de manera tácita la premisa de que «cuanto peor le fuera a España en Marruecos mejor le iría a Francia» ${ }^{33}$. Tanto el gabinete Poincaré (1922-1924) como el gabinete Herriot (19241925) mostraron así su aquiescencia con una política de actuación colonial (evitar activamente la colaboración con los españoles) que entraba hasta cierto punto en contradicción con los principios del Tratado de Protectorado de 1912 y en la que las experiencias del Residente General durante la Gran Guerra tuvieron una influencia destacada. ${ }^{34}$

Estas contradicciones se manifestaron cuando el gobierno de coalición de izquierdas de Paul Painlevé (17 de abril-28 de noviembre 1925) intentó variar el signo de la acción militar francesa en Marruecos - por primera vez desde 1912 - a través de la cooperación militar con las autoridades españolas, cada vez más apremiante tras la ruptura del frente francés por parte de las harkas rifeñas en abril de 1925. Las iniciativas del gobierno francés encontraron entonces la firme y manifiesta oposición de Lyautey, repetidamente expresada en su correspondencia con el gobierno de París ${ }^{35}$. Estos documentos revelaron no sólo la firmeza de la postura del Residente general — Lyautey había llegado a decir que dicha colaboración sólo le sería impuesta «por la fuerza» deraciones estratégicas de su propio gobierno ${ }^{36}$. La presión por parte del Foreign Office para la facilitar la colaboración de Francia y España tras los sucesos del Rif - sobre todo a la luz del cariz inquietante que estaba tomando la situación en Marruecos - puso al Mariscal en una posición insostenible ${ }^{37}$. Cuando Lyautey se vio continuamente requerido a reconsiderar su postura con respecto a la colaboración militar con los españoles respondió con opiniones y alternativas (algunas de ellas un tanto disparatadas) que revelaron la escasa sintonía de sus opiniones con las prioridades de la metrópoli, deseosa de una pronta conclusión del conflicto ${ }^{38}$. El peso de dicha falta de correspon-

33 CARAN, L., legajo 475 AP/86, Lyautey a Herriot, 28/10/24.

34 ADMAE, M., legajo. 197, Poincaré a Lyautey, 3/4/24. ADMAE, M., legajo 199, Herriot a Lyautey, 5/12/24. Véase también, sobre este particular, RIVET, 1988: 267-268.

35 ADMAE, M., legajo 94, Lyautey a Painlevé, 29/4/25 y 19/6/25.

36 ADMAE, M., legajo 197, nota a Cuverville, 4/3/24.

37 Chamberlain manifestó de manera clara la prioridad británica de una pronta solución al conflicto y así se lo hizo saber al embajador británico en Madrid (PRO FO legajo 371/11080, a Rumbold, 21/5/25) y al embajador francés en Londres (ADMAE, M., leg. 199, a Fleuriau, 6/1/25).

38 Lyautey llegó a proponer la concesión de un cierto grado de independencia al Rif y el nombramiento de Abd el Krim como Jalifa del territorio (CARAN, L., legajo 475 AP/99, a Briand, 5/7/25), propuesta que fue prontamente rechazada por el gobierno francés (ADMAE, M., legajo 77, Briand a Lyautey, 7/7/25). 
dencia en la eventual dimisión y el remplazo de Lyautey por Pétain continúa siendo objeto de debate entre los historiadores ${ }^{39}$.

En definitiva, podría concluirse que la actitud general de las autoridades francesas durante la guerra del Rif —repetidamente descrita por la historiografía como distante, inhibida, alejada y recelosa en cuanto a la colaboración con los españoles - no estaba basada exclusivamente (ni quizás fundamentalmente) en consideraciones tácticas y estratégicas (protección de la zona francesa, aislamiento de los acontecimientos de la zona española), sino también en valoraciones hasta cierto punto particulares sobre la historia y el sentido de la presencia militar de España en Marruecos y sobre la trayectoria de su ejército colonial, en las que la opinión de Lyautey resultó determinante. El remplazo de Lyautey por Pétain y el fin de la guerra del Rif pusieron de relieve, quizá a posteriori, el limitado fundamento de algunas de las prevenciones del anterior Residente General $\mathrm{y}$ revelaron las posibilidades que un enfoque distinto y otras consideraciones menos irreductibles podían ofrecer (junto con una buena dosis de suerte) en la resolución del conflicto. Todo ello se enmarcó en el nuevo clima de entendimiento establecido entre Primo de Rivera y Pétain a partir de 1925, que resaltó, por otra parte, hasta qué punto el estado anterior de las relaciones francoespañolas en Marruecos había dependido de la presencia y actitudes del anterior Residente General ${ }^{40}$. La actitud general hacia el ejército español mejoró significativamente a partir del final del conflicto del Rif, tanto entre las autoridades británicas, unánimes entonces en señalar las virtudes de los nuevos mandos militares en Marruecos, como en las francesas, por primera vez desde $1912^{41}$.

\section{LA DESORIENTACIÓN DE LA POLÍTICA COLONIAL ESPAÑOLA Y SUS REPERCU- SIONES DIPLOMÁTICAS}

La política colonial española en Marruecos se distinguió tempranamente en los informes de las autoridades británicas y francesas por reflejar las con-

39 Mientras que algunos autores se inclinan a considerar motivos hasta cierto punto ajenos al desarrollo de las campañas del Rif como explicación de la sustitución de Lyautey (cuestiones de salud, oposición a Lyautey en los círculos políticos y parlamentarios parisinos), otros consideran que el Residente General fue reemplazado por motivos de carácter diplomático y estratégico relacionados con el conflicto. En el primer caso, véase RIVET, 1988, vol 3: 299; TEYSSIER, 2004: 389-390 y SINGER y LANGDON, 2004: 212-215; en el segundo, PORCH, 1986: 297, y GERSHOVICH, 24/1 (Durham, 2004): 139-146.

40 Secretario de la embajada británica en Madrid, Mr. Gurney, a Chamberlain (PRO FO legajo 371/11079, 12/9/25).

${ }^{41}$ Los informes del Ministro Plenipotenciario y Delegado de la Residencia Francesa en Marruecos, Blanc, a Briand, (ADMAE, M., legajo 18411/10/27) y del Cónsul General británico en Tánger, Mr Gurney, al ministro de Exteriores Henderson (PRO FO, legajo 371/15009, 11/11/1930), así lo confirmaron. 
tradicciones y carencias de España como potencia imperial (escasez de medios, falta de recursos económicos, limitado desarrollo del elemento civil, dependencia del poder militar) y por su consiguiente falta de orientación, sujeta tanto a los vaivenes políticos de la Península como a las rivalidades en el seno del Ejército ${ }^{42}$. La percepción negativa sobre el Ejército de África se completó así con una visión generalmente derogatoria de la política colonial española, en un proceso paralelo y similar al anterior, que acabaría también atravesando diversas etapas

Durante los primeros años de su mandato, las objeciones fundamentales del Mariscal Lyautey hacia la temprana administración española en Marruecos se basaron sobre todo en sus carencias «culturales» o «espirituales», que el Residente General resumía en la falta de comprensión y sintonía de las autoridades españolas con el «alma marroquí» y en su escasa delicadeza y perspicacia para apreciar las características singulares e íntimas del pueblo que se les había confiado en su misión colonizadora. De acuerdo con Lyautey, el marroquí era un pueblo singular, sofisticado y orgulloso, perteneciente a un imperio ancestral y celoso de su independencia y costumbres. Estas características, sin embargo, parecían ser ignoradas por la administración española, cuyo trato con los nativos reflejaba una escasa delicadeza, un desconocimiento casi total de los usos, costumbres, tradiciones, prácticas religiosas y lenguas indígenas, una falta evidente de entendimiento de la realidad geográfica del Protectorado y, en definitiva, una completa ignorancia y aprecio por el «ser marroquí». Habiendo compartido experiencias previas en otros lugares del Imperio francés en el norte de África, a Lyautey y a otros mandos franceses les resultaba difícil aceptar la cortedad de miras y la torpeza de los métodos coloniales españoles, la escasa altura de sus objetivos y el primitivismo de sus ambiciones ${ }^{43}$. El Residente General francés incidió especialmente en la falta de talla moral y espiritual de las autoridades españolas para la tarea encomendada y en la «extrema susceptibilidad española» ante cualquier crítica o recomendación ${ }^{44}$. Las comparaciones con la zona francesa fueron frecuentes y obvias, e inevitablemente decantadas a favor de la segunda ${ }^{45}$.

No resultaba sencillo tampoco para los representantes de la Corona Británica comprender la tónica general de la administración española y sus prácticas colonizadoras en estos primeros años. Más que la falta de percepción y

42 PRO FO, legajo 185/1180, Hardinge a Grey, 3/7/14 y CADN, CD52A, Lyautey a Delcassé, 22/11/14. Algunas de estas consideraciones se recogen también en RIVET, 1988, tomo 3: 266-271; GERSHOVICH, 2000: 126-127 y SINGER y LANGDON, 2004: 212.

43 ADMAE, M., legajo 1659, Lyautey a Viviani, ministro de Asuntos Exteriores, 22/12/15 y CADN, CD166, Lyautey a Delcassé, 22/9/15.

44 CADN, legajo CD52A, Lyautey a Delcassé, 22/11/14.

45 ADMAE, M., leg. 1656, Lyautey a Briand, 8/4/1916. Véase HOISINGTON 5/1 (London, 2000): 100-102. 
sensibilidad con respecto al elemento indígena, lo que más parecía sorprender a los delegados británicos de Tánger y Tetuán era «el deplorable estado de desorden e irregularidad», la completa ausencia de previsión, de planificación y de estrategia, la improvisación de las autoridades españolas, la contradicción de sus medidas y la ineficacia resultante ${ }^{46}$. Las críticas formuladas por las autoridades británicas, que fueron numerosas, provenían de un enfoque más práctico que teórico. La escasa organización de dependencias y departamentos, el solapamiento entre la autoridad civil y militar, las carencias de material y formación, la inexistencia de infraestructuras y la imprevisión general, eran algunos de los muchos problemas a los que las autoridades británicas se referían como dificultades insolubles en las Comandancias de Ceuta y Melilla $^{47}$. A las autoridades británicas les resultaba difícil creer que no existiera control sobre estas prácticas y, especialmente, la aparente apatía con que se permitían y el fatalismo para ellos incomprensible con que se aceptaba la situación por parte de las autoridades españolas ${ }^{48}$.

A estos aspectos generales sobre la administración española, se añadieron algunas observaciones, quizá menos conocidas, sobre los propios dirigentes y responsables de la política colonial que revelaron también una disposición crítica hacia los mismos. El rey Alfonso XIII, por ejemplo, no gozaba de muchas simpatías en Marruecos. Lyautey consideraba que su actitud durante la Gran Guerra había puesto de manifiesto una íntima francofobia y una enorme ingratitud a Francia tras las iniciales aperturas diplomáticas que tuvieron lugar con la firma del Tratado de Protectorado (en las que había participado el propio Lyautey). Lyautey no tenía una opinión excesivamente elevada del monarca español, al que consideraba irreflexivo e ignorante en asuntos coloniales ${ }^{49}$. Otros diplomáticos británicos compartían también esta idea, llegando a aventurar — con enorme precisión - que su vinculación personal con la empresa marroquí acabaría creando problemas a la monarquía ${ }^{50}$.

La valoración sobre otros líderes políticos españoles tampoco resultaba excesivamente elogiosa. De todos los jefes de gobierno que se habían sucedido en Madrid desde 1912, Lyautey consideraba que tan sólo Antonio Maura (jefe de gobierno en 1918 y 1921) había mostrado una estrategia colonial coherente basada en su realismo sobre las posibilidades de España. El resto de los políticos españoles, incluyendo Romanones (que gustaba de presentarse

46 PRO FO legajo 371/4518, Atkinson a Curzon, 29/1/20 y PRO FO legajo 413/59, White a Grey, 23/11/13. Las diferencias en la mentalidad colonial de ambos países se exploran en LANGE, MAHONEY, VOM HAU 111/5, (Chicago, 2006): 1412-1462.

47 PRO FO, legajo 413/59, Kennard a Grey, 28/06/1913.

48 PRO FO, legajo 371/4525, Atkinson, vice-cónsul británico en Tetuán, a Mr Kerr, secretario del consulado de Tánger, 8/6/1920.

49 ADMAE, M., legajo 197, Lyautey a Poincaré, 22/3/24.

50 PRO FO, legajo 636/6, Hope Gill a MacDonald, 21/7/24. 
como francófilo), eran, para el Residente General francés, tan sólo una colección de representantes de segunda fila que desconocían la verdadera realidad marroquí ${ }^{51}$. Una impresión similar se desprendía del temprano informe elaborado por el embajador británico en Madrid, Mr. Hardinge, que, tras una extensa gira por Marruecos en 1914, afirmó que el gobierno español parecía estar «paralizado por su miedo a que un movimiento de avance» pudiera «conllevar una larga lista de heridos, lo que produciría una tormenta en las Cortes». El gabinete Dato, según Hardinge, parecía esperar que los generales sometieran «un país salvaje y difícil como el Rif [...], sin arriesgar vidas entre los soldados que deben llevar a cabo esta misión $\rangle^{52}$. En lo relativo a las autoridades militares, las opiniones no eran muy diferentes. De todos los Altos Comisarios españoles que se habían sucedido en Tetuán - testimonio de las frecuentes variaciones de la política colonial española en contraste con la continuidad francesa- Lyautey estimaba que tan sólo Berenguer había sido digno de dicha posición («el único español inteligente que ha estado nunca en Marruecos», dijo de él), considerando a sus antecesores (particularmente a Alfau y Marina) como jefes inexpertos y escasamente preparados, cuyos nombramientos habían sido debidos a maquinaciones políticas y contactos personales ${ }^{53}$. Algo similar se desprendía de los informes del vice-cónsul británico en Tetuán, Mr. Atkinson, para quien tan sólo el general Berenguer había sido capaz de dotar de unidad y coherencia al esfuerzo colonial de España desde $1912^{54}$.

Las opiniones escasamente favorables sobre los responsables de la política colonial española tuvieron una influencia en la escasez de contactos diplomáticos entre la Residencia General francesa y las autoridades de Ceuta y Tetuán. Aunque, como Lyautey explicó a su gobierno, existían motivos estratégicos para fomentar esta postura, resultaba evidente que bajo la misma se encontraban antipatías y recelos de carácter personal ${ }^{55}$. Estas fueron percibidas por el delegado británico en Tánger, para quien la Residencia General francesa era «demasiado militar en su gestión de gobierno y en sus relaciones con los representantes extranjeros», y no tenía suficientemente en cuenta «las susceptibilidades de los españoles», quienes, por otra parte, les daban «considerable causa de irritación $»^{56}$.

Numerosos ejemplos pueden ayudar a ilustrar esta situación. En un viaje a Francia realizado por motivos de salud a comienzos de 1922, el Mariscal

51 ADMAE, M., legajo 197, a Poincaré, 22/3/24.

52 PRO FO, legajo 185/1180, Hardinge a Grey, 3/7/14. Estas opiniones coincidían con las de su predecesor en el cargo, Maurice de Bunsen (PRO FO, legajo 185/1157, a Grey, 24/6/13).

53 PRO FO legajo 413/69, Cónsul Gral. de Tánger, Clive a Curzon. Las opiniones de Lyautey en ADMAE, legajo 1652, Lyautey a Delcassé, 8/5/15.

54 PRO FO, legajo 413/62, Atkinson a White, cónsul general en Tánger, 25/7/22.

55 CADN, legajo CD243, Lyautey a Poincaré, 21/3/24.

56 PRO FO, legajo 371/2410, White a Grey, 28/12/14. 
Lyautey se había cuidado de viajar de incógnito y de no dar a su trayecto un carácter oficial, entre otras razones, para no verse en la necesidad de detenerse en España y entrevistarse con las autoridades españolas y, especialmente, con el rey Alfonso XIII. Desafortunadamente para él, el barco que le llevaba de vuelta desde Marsella a Marruecos se vio obligado a atracar en Valencia debido al mal tiempo, con lo que, pese a su irritación evidente, Lyautey se vio obligado a corresponder a una apremiante invitación del monarca para celebrar una entrevista en Madrid. Sus comentarios posteriores sobre el incidente, relatados a sus más íntimos allegados, no dejaron lugar a dudas sobre el disgusto que dicha situación causó al Residente General ${ }^{57}$. El incidente tuvo lugar en un momento en el que la Residencia General francesa desaconsejaba la celebración de contactos públicos con las autoridades españolas ante el curso de los sucesos del Rif (marzo de 1922). Un incidente similar se repetiría en 1924, pero entonces Lyautey rehusó, ya de manera inequívoca, la celebración de una entrevista con el Rey de España ${ }^{58}$.

Otro ejemplo de estas repercusiones diplomáticas se produjo durante el periodo del gabinete militar de Primo de Rivera, que buscaba promover un mayor acercamiento y cooperación con las autoridades francesas en Marruecos. La velada negativa inicial de Lyautey a entrevistarse con Primo de Rivera — $\$$ Primo de Riveira», en sus informes-, a pesar de los deseos del nuevo dictador español de celebrar un encuentro con él, y el respaldo del gobierno francés ante estas precauciones resaltaron esta falta de reciprocidad ${ }^{59}$. Las reticencias de Lyautey se manifestaron en indirectas dilaciones y aplazamientos que dieron lugar al hecho inusitado de que Primo de Rivera visitara finalmente la Zona de Protectorado Francés sin llegar a entrevistarse con él (Lyautey había desaconsejado, por otra parte, dar publicidad y carácter oficial a esta visita ${ }^{60}$.

No se trataba exclusivamente de aspectos estratégicos los que desaconsejaban una cooperación pública y visible entre las autoridades francesas y españolas en Marruecos, como pretendía Lyautey. Estos incidentes diplomáticos aislados y otros similares - Primo fue insultado, por ejemplo, en un acto oficial por un miembro de la administración francesa al que Lyautey trató posteriormente con enorme benevolencia, lo que provocó una protesta de la

57 Así los relató el embajador francés en España, Defrance, a Poincaré, ADMAE, M., legajo $425,30 / 3 / 22$.

58 De dicha entrevista afirmó Lyautey que «no servirá para nada porque todos parten de ideas preconcebidas totalmente opuestas». (CARAN, L., legajo 475 AP/86, Lyautey a Herriot $8 / 10 / 24)$.

59 De acuerdo con el cónsul británico en Tánger, Lyautey, «despreciaba» a Primo de Rivera (PRO FO, legajo 413/69, Clive a Curzon, 28/2/23). Según las declaraciones del propio Mariscal, Primo de Rivera «no entendía lo que estaba ocurriendo en Marruecos» (ADMAE, M., legajo 76, Lyautey a Herriot, 19/7/24).

60 CADN, legajo CD243, Lyautey a Herriot, 18/7/24. 
diplomacia española - dejaron traslucir que existía cierto clima de animadversión que continuó enrareciendo las relaciones entre ambos países ${ }^{61}$. Las autoridades coloniales británicas, a pesar de compartir muchos recelos sobre la valía de los representantes civiles y militares españoles en Marruecos (a quienes el cónsul británico en Tetuán consideraba «fundamentalmente incapaces» de administrar el territorio), no perdieron en cambio ocasión de entrevistarse, visitar y establecer correspondencia con autoridades españolas y francesas a fin de promover la cooperación internacional en Marruecos ${ }^{62}$. En cuestiones relacionadas con prioridades estratégicas, los dictados del Foreign Office fueron seguidos sin vacilaciones - la postura española continuó siendo marginada en las conversaciones sobre el futuro de Tánger, por ejemplo, y se rechazaron propuestas que sugerían cambios en el statu quo del Mediterráneo Occidental- En cuestiones relacionadas con el statu quo marroquí, sin embargo, se favoreció decididamente la cooperación franco-española y el contacto con las autoridades respectivas de ambos países ${ }^{63}$.

La historiografía ha reconocido, de manera general, la influencia de las tensiones diplomáticas entre Francia y España en las dificultades, el estancamiento y la escasa cooperación entre ambas potencias en Marruecos ${ }^{64}$. Un nivel de análisis un tanto más detallado permite y revelar hasta qué punto el peso de percepciones y valoraciones de carácter personal tuvo una influencia significativa en dicho distanciamiento. Ello permite también verificar un cambio en el clima de las relaciones franco-españolas en Marruecos, tras la derrota de Abd el Krim y el fin del conflicto del Rif, del que emergieron opiniones más positivas sobre las nuevas autoridades civiles y militares instaladas en el territorio, tanto por parte francesa como por parte británica ${ }^{65}$.

61 «Imbécil», «ignorante»y «político funesto» fueron los términos empleados en el incidente. La protesta oficial ante la Embajada francesa en Madrid se presentó el 19 de julio de 1925 (ADMAE, M., legajo 77, Peretti, embajador francés en Madrid, a Briand, 19/7/25). Dichos sucesos dieron lugar a una admonición a Lyautey por parte del Quai d'Orsay (ADMAE, legajo 77, Briand a Lyautey, 20/7/25).

62 PRO FO, legajo 636/6, Hope Gill, Consul General en Tetuán, a MacDonald, ministro de Exteriores, 8/8/24.

63 Las prioridades del Foreign Office en Marruecos fueron claramente delineadas en las directrices de Villiers, Director del Departamento Occidental (PRO FO, legajo 371/11074, 19/6/25) y en las instrucciones de Chamberlain (PRO FO, legajo 371/11078, a Clive, Cónsul General en Tánger, 8/7/25).

64 Véase RIVET, 1988, vol. 3: 266-271; GERSHOVICH, 2000: 126-127; SINGER y LANGDON, 2004: 212.

65 ADMAE, M., legajo. 626, Steeg a Briand, 21/11/27 y PRO FO CO, legajo 91/489/10, Atkinson a Secretario de Estado de las Colonias, Leo Amery, 30/10/29. 


\section{LOS SUCESOS DE JULIO DE 1936}

La atención de los historiadores se ha dirigido con frecuencia, en los últimos años, a explorar los acontecimientos de la otra orilla del Estrecho para indagar en los orígenes de la Guerra Civil española. Este interés, que ha permitido clarificar y evaluar particularmente la influencia del Ejército de África en el inicio y desarrollo del conflicto, no se ha extendido habitualmente a las percepciones, actitudes y recomendaciones de los representantes coloniales británicos y franceses, un factor que, sin embargo, puede contribuir a explicar la interpretación de los sucesos de julio de 1936 por parte de los gobiernos francés y británico y su postura inicial ante los mismos ${ }^{66}$. Esta sección intentará enmarcar quizá con más precisión estas reacciones y relacionarlas con las vicisitudes de la colonización española en Marruecos.

De manera breve, podría comenzarse diciendo, por tanto, que los cambios iniciales introducidos por el gobierno Azaña en 1931 encontraron entre los observadores extranjeros una respuesta mixta y algunas valoraciones dubitativas, que cuestionaron tempranamente su eficacia para la continuidad de la labor española en Marruecos y su conveniencia para mantener la cordialidad de las relaciones entre Francia y España. Estas aprensiones tuvieron dos dimensiones fundamentales, que se refirieron a los continuos cambios de atribuciones y personal en el Ejército de África, en primer lugar, y a la política española con respecto al nacionalismo marroquí, en segundo término.

En lo que se refiere a las autoridades civiles y militares del territorio, pronto se desarrolló entre los representantes coloniales franceses y británicos un cierto consenso referido a las iniciales reformas del gobierno Azaña. Estos informes se mostraron comprensivos, en su mayoría, con el hecho de que el gobierno republicano quisiera reducir gastos en Marruecos (sobre todo en el contexto internacional de comienzo de los años 30), y también asegurar la fidelidad al régimen de los militares africanos (tras el fallido golpe de Estado de 1932). Sin embargo, aparecieron también en ellos críticas vehementes con respecto al hecho de que, lejos de neutralizar políticamente al Ejército de África, el gobierno Azaña estaba, por el contrario, instigando su politización a través de la promoción ostentosa y evidente de mandos públicamente adeptos al régimen y el relegamiento de aquellos percibidos como menos afines al mismo ${ }^{67}$. Junto con otras medidas, como los recortes en servicios y personal,

66 Ésta es una dimensión que se echa en falta en algunas de las obras sobre el tema: MORADIELLOS 1996; BALFOUR, 2002; RIVIÈRE 2006. Un balance de las coordenadas internacionales del periodo en NEILA y PEREIRA 34/1 (Bilbao, 2007): 117-154.

67 Algunos representantes británicos llegaron a asimilar el proceso con el de «un terremoto en un área volcánica» (PRO FO, legajo 371/15745, Chafy, vicecónsul en Tetuán, a Henderson, 19/5/31). Comentarios similares en ADMAE, M., leg. 205, Blanc, a Herriot, 13/9/32. 
se cuestionó particularmente el hecho de que la labor colonizadora en la zona española se estaba viendo progresivamente afectada por los vaivenes políticos de la Península ${ }^{68}$. El continuo cambio de mandos, el reemplazo de jefes de probada capacidad por otros con credenciales más cercanas al régimen, la ruptura de la continuidad de la política colonial y la falta de dirección resultante, fueron aspectos repetidamente citados en la correspondencia oficial. Y ello no sólo en lo referido al primer gobierno de la República —a quien numerosos observadores consideraban principal responsable del inicio de la situación—, sino también a los gobiernos de los años 1933-1935, que llevaron a cabo una revocación general de las prioridades de la política colonial y una recuperación apresurada de los oficiales marginados por el anterior gobierno Azaña. Las críticas contra la politización del Ejército de África se vincularon también con la creciente ineficacia de la administración española en Marruecos, en lo que se consideró generalmente como un retroceso general sobre los éxitos conseguidos en los años precedentes: «El panorama doméstico en España — resumía el cónsul francés en Tetuán en 1923 - no permite al gobierno dar a los asuntos de Marruecos ni el tiempo que requieren ni la firmeza de orientación que demandan $»^{69}$. Algunas autoridades británicas también apuntaron ya entonces la grave amenaza a la que el gobierno republicano estaba haciendo frente en Marruecos, donde el empuje renovado de fuerzas consideradas «revolucionarias» no encontraba ante ellas sino autoridades débiles que se debatían entre la indecisión y la ambigüedad ${ }^{70}$.

Otra crítica fundamental, como se ha dicho, se refería a la actitud de las autoridades españolas con respecto al nacionalismo marroquí. La nueva orientación iniciada por el gobierno de Azaña - y que sin excesivos cambios prolongarían los gobiernos del periodo 1933-1935- encontró en representantes británicos y franceses motivos de preocupación y condena. A juicio de las autoridades francesas, la actitud indolente y benévola de los representantes españoles en su trato con los líderes nacionalistas (sobre todo en Ceuta, Melilla y Tetuán, donde el naciente movimiento había comenzado a adquirir más relevancia) denotaban falta de firmeza y escasa comprensión sobre la amenaza del nacionalismo marroquí. Mandos militares cercanos a la Residencia francesa consideraban inaceptable que España no adecuara y coordinara su política indígena con la de Francia, mucho más firme en su postura con respecto a las aspiraciones nacionalistas. Del mismo modo, entendían que España no era consciente del peligro que el nacionalismo marroquí representaba

68 Así pareció entenderlo también el Quai d'Orsay (ADMAE, M., legajo 204, Laval, ministro de Exteriores, a Saint, 3/2/32).

69 ADMAE, M., legajo 205, Serra a Boncour, ministro de Exteriores, 28/1/33.

70 PRO FO, legajo 371/19708, Cónsul General británico en Tánger, Gye, a Sir Samuel Hoare, ministro de Exteriores, 22/7/35. 
(por su potencial confluencia con otros movimientos panislámicos de carácter anti-occidental) y consideraban que las autoridades republicanas se habían dejado llevar por un ingenuo idealismo que podía tener graves consecuencias $^{71}$.

Los representantes británicos encontraban también difícil de explicar la actitud de las autoridades españolas, sobre todo en lugares como Tetuán, donde existía la impresión de que los nacionalistas podían actuar con mayor comodidad que en la propia zona francesa (de hecho, muchos huían allí desde el Protectorado francés). Conscientes de los peligros de la expansión del nacionalismo árabe, los observadores británicos consideraban particularmente inaceptable no tanto el talante conciliador de las autoridades españolas, sino la proliferación de muestras de camaradería que prodigaban hacia el elemento indígena, que ellos juzgaban inadmisibles. La preocupación fundamental de las autoridades británicas, como ya se mencionó anteriormente, se refería a un elemento básico del orden colonial europeo (la diferenciación racial entre protectores y protegidos y la superioridad de los primeros sobre los segundos), de ahí que observaran con incredulidad e inquietud las muestras de solidaridad y "hermanamiento» entre las autoridades españolas y las marroquíes. El cónsul británico en Tetuán se mostraba particularmente adverso ante esta «desafortunada tendencia de los residentes españoles en la zona a mirar a los moros como sus hermanos de sangre», y ante su "creencia en la igualdad entre español y moro», que él atribuía a «la ausencia de una política definida en la administración» ${ }^{72}$.

Estas apreciaciones tuvieron como consecuencia fundamental extender progresivamente en el Protectorado francés y entre los consulados y delegaciones británicas en Marruecos las dudas y la creciente desconfianza hacia la política colonial de la Segunda República ${ }^{73}$. Del mismo modo, fueron recibidas en el Quai d'Orsay y en el Foreign Office con una evidente preocupación. En un largo memorándum redactado por el Foreign Office en 1933, se señalaron como problemas fundamentales de la posición británica en Marruecos la creciente presencia de elementos comunistas y revolucionarios en el Protectorado - sobre todo en la zona española - y las potenciales consecuencias de su actividad en otras regiones del Imperio Británico ${ }^{74}$. El gobierno francés, por su parte, identificó el peligro nacionalista como la principal amenaza a sus intereses en Marruecos, vinculándola de manera directa con la inacción de las autori-

71 ADMAE, M., legajo 83, Residente General Saint a Boncour, 31/7/33 y SHAT, legajo 3H260, Residente General Ponsot a Laval, 3/1/35).

72 PRO FO 371/17397, Monck-Mason a Sir John Simon, 3/7/33.

73 Esta evidencia parece cuestionar la solvencia de la política colonial de la Segunda República, defendida por autores como FLEMING 13/1-2 (London, 1998): 80-98.

74 PRO FO 371/15745, C.N. Stirling, Memorándum, 28/12/1933. Este aspecto se visita en THOMAS, 2005: 312-347. 
dades españolas ${ }^{75}$. La reacción de ambos gobiernos no se hizo esperar: tanto los representantes británicos en Tánger como las autoridades de Rabat recibieron instrucciones para hacer llegar a las autoridades coloniales españolas su preocupación por el deterioro de la autoridad en la zona española y las consecuencias que de ella podían derivarse para el resto del Protectorado ${ }^{76}$.

Lejos de mejorar, a partir de octubre de 1934, y desde entonces hasta julio de 1936, la situación en Marruecos comenzó a adoptar carices verdaderamente preocupantes, a juicio de las autoridades francesas y británicas. Éstas llegaron a la temprana conclusión de que Marruecos estaba pasando a formar parte de una manera casi irreversible de la radical polarización política que estaba desarrollándose en la Península. La participación de unidades del Ejército de África en la represión de los sucesos de Asturias en 1934 no hizo sino confirmar esta impresión. A su retorno a Marruecos, los nombres de Franco y otros jefes militares «jóvenes, capaces y enérgicos», que pertenecían a unidades de la Legión y los Regulares, comenzaron ya a identificarse en las fuentes británicas y francesas como los mandos militares más sobresalientes y capaces del Ejército de África y, ante el progresivo deterioro de la situación en la zona española, como la esperanza más sólida ante la amenaza revolucionaria ${ }^{77}$.

A partir de las elecciones de febrero de 1936, las autoridades españolas en Marruecos no sólo fueron acusadas de incompetencia para mantener el orden y la autoridad en la zona española, sino también de complicidad creciente con las fuerzas sindicalistas y comunistas, enormemente activas desde entonces en Melilla, Ceuta y Tánger. Particularmente en el caso de Tánger, se produjeron tiroteos, huelgas, cierre de fábricas, manifestaciones violentas y la clausura del puerto, lo que produjo una impresión penosa entre los diplomáticos europeos, cuyos informes señalaron ya unánimemente a las autoridades españolas como cómplices de la situación. De acuerdo con el cónsul británico en Tánger, Mr Ellis, los sucesos de Tánger a comienzos de 1936 demostraron que el gobierno del Frente Popular era incapaz de (y estaba lejos de desear) contener la marea revolucionaria en Marruecos, donde el comunismo internacional financiado por Moscú estaba intentando subvertir el orden social del Protectorado, con el fin de promover una reacción anti-colonial que destruye-

75 Maginot, Ministro de Guerra, a Briand, ministro de Asuntos Exteriores (SHAT, legajo 3H139, 28/4/31).

76 CARAN, legajo F/60/769/2, Ministerio de la Guerra, Boletín de Información sobre cuestiones musulmanas, 7/4/33 y ADMAE, M., legajo 186, Herriot a Herbette, embajador francés en España 12/9/32. El cónsul general británico en Rabat, Mr. Bullard, también recibió instrucciones expresas de Anthony Eden (PRO FO 371/20502, 1/5/36).

77 PRO FO, legajo, 425/412, Heywood, agregado militar de la embajada británica en Madrid, a Hoare, 12/6/35. Valoraciones similares en PRO FO, legajo 371/18557, Monck-Mason a Simon, 7/12/34; y ADMAE, legajo 85, Reny, cónsul francés en Tetuán, a Laval, 20/5/35. 
ra los imperios europeos ${ }^{78}$. Asimismo, el Ministro plenipotenciario del Consulado general de Francia en Tánger, consideraba que la ciudad estaba siendo víctima del «sindicalismo libertario» que estaba reduciendo a España «a sangre y fuego» y que debía combatirse con todos los medios disponibles ${ }^{79}$.

Estas valoraciones ahondaron las preocupaciones que ya se habían ido extendiendo en desde comienzos de los años 30 tanto en el Quai d'Orsay como en el Foreign Office, donde con frecuencia se señalaba que la situación de la zona española en Marruecos parecía estar escapando al control de la Segunda República ${ }^{80}$. La creciente visibilidad de los elementos nacionalistas en la zona española pareció convencer a las autoridades coloniales francesas de que la mayor amenaza a la que hacía frente el Protectorado francés en Marruecos se derivaba del desgobierno de la Segunda República ${ }^{81}$. Los acontecimientos ocurridos en Tánger, por su parte, extendieron entre los representantes británicos la creencia general de que la Segunda República era verdaderamente incapaz de contener la marea revolucionaria ${ }^{82}$.

El inicio de la sublevación militar de julio de 1936 — anticipada en diversos momentos por estas mismas fuentes ${ }^{83}$ — encontró en las autoridades francesas y británicas una actitud de cierta anticipación y prevención, que se tradujo en una interpretación parcial de la misma. El alzamiento del 17 de julio se entendió, de manera general (y así se explicó en informes dirigidos a la metrópoli), como una reacción de aquellas unidades del Ejército más comprometidas con la labor colonial, que se habían visto exasperadas por la conducta de la Segunda República en Marruecos, abandonadas por la misma frente a las críticas de una opinión pública cada vez más radicalizada, y enfrentadas directamente con la amenaza de la revolución en 1934. Según estas fuentes, las unidades del Ejército de África se habían levantado:

contra la desorganización social, las huelgas, los incendios, los abusos de poder, los arrestos arbitrarios y, en general, contra todos los atentados contra la autoridad cometidos en nombre de la defensa de la libertad desde las elecciones de febrero $^{84}$.

78 PRO FO, legajo 371/20497, Ellis a Eden 15/5/36.

79 SHAT, legajo 3H249, Delaforcade a Laval, 27/3/35.

80 PRO FO, legajo 371/20497, memorándum interno, 15/5/36.

81 CARAN, L., legajo F/60/769, Boletín sobre la situación en la zona española, marzo de 1936, p. 19.

${ }_{82}$ Correspondencia entre el cónsul-general en Rabat, Mr Bullard, y Anthony Eden, secretario del Foreign Office (PRO FO 371/20502, informe del 1 de mayo de 1936).

83 Por ejemplo, por el vicecónsul francés en Melilla, que afirmaba en mayo de 1935 que la única esperanza que quedaba a la población «sana» de Melilla era una «reacción» del ejército. SHAT, legajo 3H264, a Peyrouton, Residente General francés.

84 SHAT, legajo 3H 1421, Dirección de Asuntos Políticos de la Residencia General de la República Francesa en Marruecos, informe secreto, enero-julio 1936. 
El éxito del alzamiento militar en Marruecos y del reclutamiento entre el elemento local se interpretó desde la misma óptica, achacándolo primeramente a los fracasos de la Segunda República, a los frecuentes cambios introducidos en la labor colonial - debido más a radicalismos políticos que a verdaderas necesidades del Protectorado-, y a la incapacidad de las autoridades españolas para afrontar la situación derivada de la crisis económica de $1929 .{ }^{85}$ En mayor medida que una sublevación contra el orden constitucional vigente en la Península, por tanto, la mayoría de los informes de las autoridades coloniales británicas y francesas interpretaron el levantamiento militar como un resultado del desgobierno y la incapacidad de la Segunda República en Marruecos. La situación de miseria de muchos indígenas, por ejemplo, que muchos achacaban a la falta de planificación de la política colonial republicana, sirvió para explicar la popularidad y la afluencia de voluntarios para alistarse en un movimiento que les ofrecía paga y comida, bajo el liderazgo de jefes que contaban con enorme prestigio entre el elemento local ${ }^{86}$. En definitiva, en mayor medida que la ambición de los militares alzados contra el poder legítimo de la Península, los representantes coloniales de Francia y Gran Bretaña en Marruecos tendieron a vincular el golpe militar de Marruecos con el fracaso de la política colonial de la Segunda República y su incapacidad para hacer frente a la marea revolucionaria. Las consecuencias de dicha interpretación para la futura actitud de los gobiernos británico y francés al comienzo de la guerra civil han sido suficientemente investigadas por los historiadores ${ }^{87}$.

\section{CONCLuSión}

Los estudios sobre las relaciones internacionales en torno al Protectorado marroquí a comienzos del siglo XX han adoptado con frecuencia un enfoque geo-estratégico en el que las prioridades políticas, económicas y militares de las potencias involucradas (Inglaterra, Francia, España) han ocupado un lugar central para explicar el desenvolvimiento de las tensiones y rivalidades en el Mediterráneo Occidental. Admitiendo la importancia y coherencia de dicho contexto, este artículo ha pretendido poner de manifiesto otros elementos del mismo que han recibido escasa atención por parte de la historiografía y que refieren a un ámbito un tanto más reservado de las relaciones diplomáticas, en el que la

85 CARAN, L., legajo F/60/769, Boletín sobre la situación en la zona española, 17/7/36.

86 PRO Cabinet Office, legajo 91/500/2, Monck-Mason, Memorandum 1936, «Spanish disturbances in Morocco». Estas constantes se resaltan también en IBN AZZUZ, 1997: 77120; ALCARAZ CÁNOVAS, 2006, y TUMA (London, 2011): 91-107.

87 Entre otros, véase MORADIELLOS, 1996, 1-32; BALFOUR, 2002: 237-268 y FARRE, 2006: 202-218. 
percepción, las opiniones, valoraciones y consideraciones de los representantes británicos y franceses en Marruecos sobre la presencia y el sentido de la colonización española en Marruecos adquieren una importancia significativa.

Este artículo propone también que dichas impresiones y apreciaciones, lejos de resultar irrelevantes, tuvieron una importancia destacada en la configuración de una visión colonial sobre la presencia española en Marruecos por parte de las autoridades coloniales británicas y francesas y en las recomendaciones realizadas a sus gobiernos respectivos sobre la actitud a adoptar ante la misma. La dudosa legitimidad de la presencia española en Marruecos, las carencias del Ejército de África, las contradicciones de la administración colonial en el territorio y, particularmente, el progresivo deterioro de la autoridad española a comienzos de los años 30 fueron ejes en torno a los cuales gravitaron muchas de estas opiniones, cuya influencia en la política colonial de la metrópoli fue persuasiva y, en algunos casos, podría decirse que determinante.

Lejos de resultar unidireccional, la influencia de dichas recomendaciones se vería a su vez afectada y condicionada por las propias transformaciones políticas y los cambios de gobierno que tuvieron lugar en la metrópoli, y por los cambios de dirección en las prioridades y estrategias coloniales que resultaron de los mismos. Se manifestarían de este modo dudas y vacilaciones, en algunos casos, y resistencias en otros, ante nuevas y emergentes prioridades y políticas coloniales metropolitanas que cuestionaron la validez de dichas percepciones y valoraciones y que demandaron líneas de actuación más pragmáticas y acordes a los intereses de las potencias europeas en Marruecos.

De ambas perspectivas surgen conclusiones que ayudan a completar el cuadro de las vicisitudes del colonialismo español en Marruecos, ahondando en la percepción del mismo por parte de sus vecinos inmediatos, explorando el modo en que las mismas permearon sus informes a la metrópoli y detallando la influencia que éstas ejercieron en la toma de decisiones de sus gobiernos respectivos. Las consecuencias que se siguieron para el Protectorado español y la propia situación de la Península son difíciles de soslayar. Es interesante destacar, de manera particular, que las dificultades del colonialismo español en Marruecos a comienzos del siglo XX no provocaron cuestionamientos significativos que pudieran afectar la justificación ideológica del dominio colonial. Por el contrario, estos obstáculos se consideraron como una manifestación de las peculiaridades específicas del dominio español, presupuestos que permearon también la interpretación sobre los sucesos de julio de 1936. 


\section{BibLIOGRAFÍA}

Alcaraz Cánovas, Ignacio, Marruecos en la Guerra Civil española: los primeros siete días de sublevación y sus consecuencias, Madrid, Catriel, 2006.

Balfour, Sebastian, Abrazo mortal. De la guerra colonial a la Guerra Civil en España y Marruecos (1909-1939), Madrid, Península, 2002.

Berenson, Edward, Heroes of Empire, Berkeley, University of California Press, 2011.

Berman, Nathaniel, «'The Appeals of the Orient: Colonized desire and the War of the Riff», en Karen Knop (ed.), Gender and Human Rights, Oxford, OUP, 2004; 195 230.

Cembrero, Ignacio, Vecinos alejados. Los secretos de la crisis entre España y Marruecos, Madrid, Galaxia Gutenberg, 2006.

Charmley, J., «Living and Dying Nations» en Isabel Burdiel y Roy Church, Viejos y Nuevos Imperios. España y Gran Bretaña, Valencia, Episteme, 1998; 157-163.

De la Mata, Javier Ramiro, «España y el Protectorado en Marruecos: Aproximación a un proceso colonial», Anales de Historia Contemporánea, 24/1 (Murcia, 2008): 291-305.

Díaz Pinés y Fernández-Pacheco, Octavio, Marruecos. El Protectorado español, Madrid, Publicaciones españolas, 1953.

Faure, Guy Olivier, «Escalation of Images in International Conflict» en Francesco Aquilar y Mario Galluccio, Psychological and Political Strategies for Peace Negotiation. A Cognitive Approach, London, Springer, 2011; 99-115.

Fischer, John, «Keeping 'the Old Flag flying': the British community in Morocco and the British Morocco Merchants Association, 1914-24», Historical Research, 83/222 (London, 2010): 719-746.

Fleming, Shannon E., «Spanish Morocco and the Second Republic: Consistency in colonial policy?», Mediterranean Historical Review 13/1-2 (London, 1998): 8098.

Gershovich, Moshe, French Military Rule in Morocco. Colonialism and its Consequences, London, F. Cass, 2000.

Gershovich, Moshe, «Collaboration and 'Pacification': French Conquest, Moroccan Combatants, and the Transformation of the Middle Atlas», Comparative Studies of South Asia, Africa and the Middle East, 24/1 (Durham, 2004): 139-146.

Gillespie, Richard, «European Union responses to conflict in the western Mediterranean», The Journal of North African Studies, 15/1 (London, 2010): 85-103.

Goldgeier, James M. y Tetlock Phillip E. «Psychology and International Relations Theory», Annual Review of Political Science, 4 (Berkeley, 2001): 67-92.

Hoisington, William A., «Lyautey and the French Conquest of Morocco», London, Polvane Macmillan, 1995.

Hoisington, William A., «Designing Morocco's Future: France and the Native Policy Council, 1921-1925», The Journal of North African Studies, 5/1 (London, 2000): 63-108. 
Ibn Azzuz, Mohammad, Actitud de los moros ante el alzamiento. Marruecos, 1936, Málaga, Algazara, 1997.

Jervis, Robert, Perception and Misperception in International Politics, Princeton, PUP, 1976.

Jover Zamora, José María, Política, Diplomacia y Humanismo Popular. Estudios sobre la vida española en el siglo XIX, Madrid, Turner, 1976.

Kaki, Ait, «Les Etats du Maghreb face aux revendications berbères», Politique étrangère, 68/1, (Paris, 2003): 103-118.

Kunz, Rudibert, «'Con ayuda del más dañino de todos los gases': Der Gaskrieg gegen die Rif-Kabylen in Spanisch Marokko», en Hrsg. Susanne Meinl, Völkermord und Kriegsverbrechen in der ersten Hälfte des 20, Frankfurt am Main, Campus Verlag, 2004; 153-191.

Labanyi, Jo, «Love, Politics and the Making of the Modern European Subject: Spanish Romanticism and the Arab World», Hispanic Research Journal, $5 / 3$ (London, 2004): 229-243.

Lange, Matthew; Mahoney, James y vom Hau, Matthias, «Colonialism and Development: A Comparative Analysis of Spanish and British Colonies», American Journal of Sociology, 111/5 (Chicago, 2006): 1412-1462.

López García, Bernabé, Marruecos y España. Una historia contra toda lógica, Sevilla, Fundación Tres Culturas, 2007.

López García, Bernabé, «Un raro y desigual lote de libros sobre España y Marruecos», Revista de Estudios Internacionales Mediterráneos [en línea], 2, (2011) disponible en: http://sites.google.com/site/teimrevista/ [consultado el 10 de febrero de 2011].

Madariaga, María Rosa de, Los moros que trajo Franco: la intervención de las tropas coloniales en la Guerra Civil española, Madrid, Martínez Roca, 2002.

Madariaga, María Rosa de, Abd el-Krim El Jatabi. La lucha por la independencia, Madrid, Alianza Editorial, 2009.

Maddy-Weitzman, Bruce, The Berber Identity Movement and the Challenge to North African States, Austin, University of Texas Press, 2011.

Martin-Márquez, Susan, Disorientations: Spanish Colonialism in Africa and the Performance of Identity, New Haven, Yale University Press, 2008.

Mechbal, Adnan, «Los Moros de la Guerra Civil española: entre memoria e historia», Amnis [en línea], 2 (2011). Disponible en: http://amnis.revues.org/1487 [consultado el 10 de febrero de 2012].

Montero Jiménez, Jose Antonio, «Una puerta a los asuntos de Europa: Estados Unidos, España y la cuestión marroquí», Historia y Política, 25/1 (Madrid, 2011): 235-269.

Moradiellos, José María, La perfidia de Albión: el gobierno británico y la guerra civil española, Madrid, SXXI, 1996.

Morales Lezcano, Víctor, El colonialismo hispano-francés en Marruecos (18981927), Granada, Universidad de Granada, 2002. 
Neila Hernández, José Luis y Pereira Castañares, Juan Carlos, «La España de Alfonso XIII en el sistema internacional de posguerra (1919-1931)», Historia Contemporánea, 34/1, (Bilbao, 2007): 117-154.

Owen, Robert, «British and French Military Intelligence in Syria and Palestine, 1914-1918: Myths and Reality», British Journal of Middle Eastern Studies, 38/1 (London, 2011): 1-6.

Pastor Garrigues, Francisco Manuel, «España y la apertura de la cuestión marroquí, 1895-1912», Anales de Historia Contemporánea, 23/1 (Murcia, 2007): 147-170.

Pedraz Marcos, Azucena, Quimeras de África. La Sociedad Española de Africanistas y Colonistas: el colonialismo español de finales del siglo XIX, Madrid, Polifemo, 2000.

Porch, Douglas, The Conquest of Morocco, London, Jonathan Cape, 1986.

Porch, Douglas, «Spain's African Nightmare», Quarterly Journal of Military Histo$r y, 18$, (Leesburg, 2006): 28-37.

Rivet, Daniel, Lyautey et l'institution du Protectorat Français au Maroc, 1912-1925, Paris, L'Harmattan, 1988, vol. 3.

Rivière, Cecille, Le colonialisme espagnol au Maroc sous la Seconde République (1931-1936), Geneve, Institut universitaire de hautes études internationales, 2006.

Sasse, Dirk, Franzosen, Briten und Deutsche im Rifkrieg 1921-1926, München, Oldenbourg, 2006.

Segalla, Spencer D., The Moroccan Soul. French Education, Colonial Ethnology, and Muslim Resistance, 1912-1956, Lincoln, University of Nebraska Press, 2009.

Singer, Barret y Langdon, John, Cultured Force. Makers and Defenders of the French Colonial Empire, Madison, The University of Wisconsin Press, 2004.

Teyssier, Arnand, Lyautey, Paris, Perrin, 2004.

Thomas, Martin, The French Empire between the wars: imperialism, politics and society, Manchester, MUP, 2005.

Thomas, Martin, «Anglo-French Imperial Relations in the Arab World: Intelligence Liaison and Nationalist Disorder, 1920-1939», Diplomacy and Statecraft, 17/4 (London, 2006a): 771-798.

Thomas, Martin, «Crisis Management in Colonial Sates: Intelligence and Counterinsurgency in Morocco and Syria after the First World War», Intelligence and National Security, 21/5 (London, 2006b): 697-716.

Tuma, Ali Al, «The Participation of Moorish Troops in the Spanish Civil War (193639): Military Value, Motivations, and Religious Aspects», War \& Society, 30/2 (London, 2011), 91-107.

Tuma, Ali Al, «Tangier, Spanish Morocco and Spanish Civil War in Dutch diplomatic documents», The Journal of North African Studies, 17/3 (London, 2012): 433-453.

Recibido: 04/04/2012

Aceptado: 07/01/2013 